\title{
Wolff-Parkinson-White syndrome type B with tachycardia-dependent (phase 3) block in the accessory pathway and in left bundle-branch coexisting with rate-unrelated right bundle-branch block
}

\author{
IVAN J MENDOZA, AGUSTIN CASTELLANOS, RUEY J SUNG \\ From the Division of Cardiology', Department of Medicine, University of Miami School of Medicine, \\ Miami, Florida, USA
}

SUMMARY A patient with Wolff-Parkinson-White syndrome type B developed 2:1 atrioventricular block resulting from the association of persistent right bundle-branch block with tachycardia-dependent (phase 3) left bundle-branch block. Electrophysiological studies disclosed the coexistence of a tachycardia-dependent (phase 3) block in the accessory pathway. This conduction disturbance was exposed, not by carotid sinus massage as in previous studies, but by pacing-induced prolongation of the interval between two consecutively conducted atrial impulses. Furthermore, the surface electrocardiogram showed, at different times, ventricular complexes resulting from: (1) exclusive atrioventricular conduction through the normal pathway without bundle-branch block; (2) predominant, or exclusive, atrioventricular conduction through a right-sided accessory pathway; (3) exclusive atrioventricular conduction through the normal pathway with right bundle-branch block; (4) exclusive conduction through the normal pathway, with left bundle-branch block; (5) fusion between (1) and (2); and finally, (6) fusion between (2) and (3)

However, QRS complexes resulting from simultaneously occurring Wolff-Parkinson-White syndrome type B and left bundle-branch block could not be identified. Future electrophysiological investigations should re-evaluate the criteria used to differentiate between true and false patterns of Wolff-Parkinson-White syndrome type B coexisting with left bundle-branch block.

The association of Wolff-Parkinson-White (WPW) syndrome, either type A or type B, with right bundle-branch block has been well recognised. ${ }^{1-7}$ However, there are far fewer reports of the coexistence of left bundle-branch block with pre-

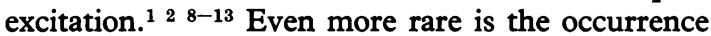
of both right and left bundle-branch block in a patient with WPW type B.

\section{Case report}

A 62-year-old woman with WPW syndrome type B and recurrent supraventricular tachycardias was referred for electrophysiological evaluation after the appearance of right bundle-branch block and 2:1 atrioventricular block. Electrocardiograms during previous admissions had also shown pure left bundle-branch block, but exclusively when the sinus cycle lengths were shorter than $620 \mathrm{~ms}$, that is when the rates were over $96 / \mathrm{min}$ (Fig. 1A). On the other hand, WPW type $B$ was seen only with longer sinus cycle lengths. For example, Fig. $1 \mathrm{~B}$ and $\mathrm{C}$ recorded while the rates ranged between 79 and $86 / \mathrm{min}$ show that the PR intervals were short $(120 \mathrm{~ms})$, the QRS complexes wide and of varying duration (100 to $130 \mathrm{~ms}$ ), and the electrical axis deviated abnormally to the left (about $-60^{\circ}$ ). Finally, Fig. 1D was obtained after pre-excitation had been abolished by the intravenous administration of $600 \mathrm{mg}$ procainamide (given at a rate of $100 \mathrm{mg}$ every five minutes). The sinus rates ranged between 79 and $83 / \mathrm{min}$. The QRS complexes were narrow, there being no evidence whatsoever of left bundle-branch block. 
In Fig. 1, physiological (rate-related) and pharmacological variations in the PR intervals prevented the comparison between the PJ (or PS) intervals occurring during left bundle-branch block, WPW type B, and normal conduction with narrow QRS complexes. Nevertheless, the effects of procainamide suggested that the pre-excitation complexes were fusion beats resulting from ventricular activation through both accessory and normal pathways (without left bundle-branch block in the latter). This assumption implies that the patient had a tachycardia-dependent (phase 3) left bundle-branch block.

Further evidence supporting the existence of a rate-related conduction disturbance in the left bundle-branch was obtained from intracardiac electrophysiological studies performed after development of right bundle-branch block. Thus, the first half of Fig. 2, recorded while the high right atrium was paced, shows 2:1 atrioventricular block. The first and third $P$ waves, reaching the ventricles exclusively through the left bundlebranch, were followed $400 \mathrm{~ms}$ later by $\mathrm{P}$ waves blocked below the site from which the $\mathrm{H}$ deflection was recorded (presumably at both bundle-branches simultaneously).

In the beats conducted with a right bundlebranch block morphology the interval between the atrial (A) deflection of the His bundle electrocardiographic lead and the onset of ventricular (V) depolarisation (wherever it might have occurred) gave a measure of conduction time through the normal (AV node-His bundle-left bundlebranch) pathway. The duration of the corresponding $\mathrm{AH}, \mathrm{HV}$, and $\mathrm{H}$ right ventricular apex (RVA) intervals was 110,50 and 85 to $90 \mathrm{~ms}$, respectively.

Since the pre-excitation had become concealed, attempts had to be made to expose, or unmask, atrioventricular conduction through the accessory pathway (Fig. 2 and 3). This was accomplished by increasing the intervals between two consecutively conducted atrial impulses by means of a single premature atrial stimulus delivered after every eighth blocked $\mathbf{P}$ wave. When these intervals were prolonged beyond $1000 \mathrm{~ms}$, they were terminated by QRS complexes (last in Fig. 2 and in Fig. 3, left panel) which were different from those with a right bundle-branch block morphology in that: (a) lead I changed to a predominantly positive deflection (not followed by a wide $S$ wave) with a slurring in its upstroke (delta wave); (b) the electrical axis was deviated abnormally to the left; and (c) lead V1 changed to an Rsr' pattern (Fig. 2) or to an Rs morphology (Fig. 3, left panel). In these complexes $\mathrm{AH}$ remained at the control value $(110 \mathrm{~ms})$ but the $\mathrm{H}$ deflection was inscribed as the ventricles started to be depolarised by the impulse emerging from the accessory pathway. In consequence, the $\mathrm{AV}$ interval of $110 \mathrm{~ms}$ was used as a rough estimate of conduction time through the accessory pathway. ${ }^{14} 15$

These findings suggested that the last QRS complexes in Fig. 2 and 3, left panel, reflect fusion resulting from ventricular activation through both
Fig. 1 Tachycardia-dependent block in the left bundle-branch and (possibly) in the accessory pathway $(A)$; different degrees of pre-excitation with WolffParkinson-White type $B$ morphologies $(B, C)$ and narrow $Q R S$ complexes after procainamide (D).

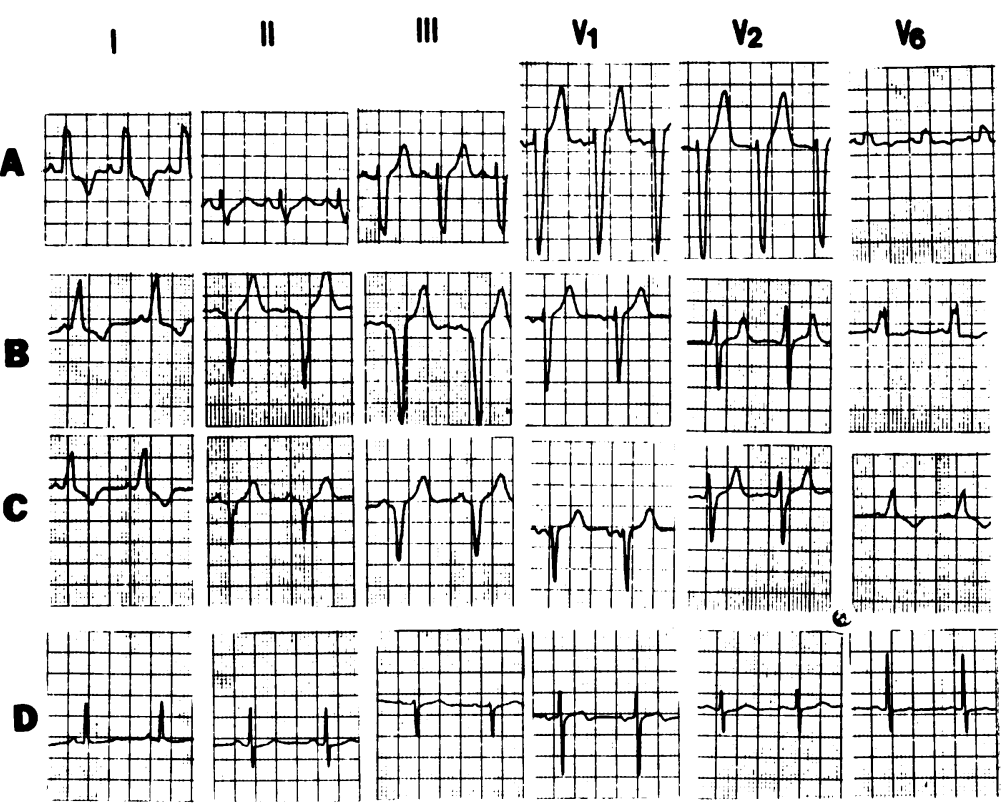


the accessory and normal pathways (with right bundle-branch block in the latter). On the other hand, the last QRS complex in Fig. 3, right panel, resulted from exclusive, or almost exclusive, conduction through the accessory pathway. It thus had a morphology similar to that in Fig. 1B.

Whenever pre-excitation occurred, the $\mathrm{HV}$ intervals, as well as the His-right ventricular apex (H-RVA) intervals, were shorter than in control complexes, indicating that the apex of the right ventricle was not activated by the impulse traversing the normal pathway, but by that emerging from the accessory pathway..$^{14} 15$ Therefore, the time elapsing between the onset of the delta wave and arrival of excitation at the RVA ( $35 \mathrm{~ms}$ ) was used to estimate conduction time from pre-excitated site to the apex of the right ventricle. ${ }^{14}{ }^{15}$ Moreover, if the AV interval (of $105 \mathrm{~ms}$ ) preceding the ventricular complexes with a delta wave indeed reflected the conduction time through the accessory pathway, then the fusion complexes in Fig. 2 and 3 can be explained by assuming that the corresponding $\mathrm{AH}$ interval of $110 \mathrm{~ms}$ still allowed certain portions of the left ventricle to be activated by the impulse descending through the left bundle-branch. ${ }^{14} 15$

However, the increase of the AH interval to $140 \mathrm{~ms}$ which occurred in the last complex of the right panel of Fig. 3 (in turn resulting from the concealed penetration, into the atrioventricular node, of the preceding, premature, atrial beats) produced sufficient delay in the conduction of the impulse traversing the normal pathway so as to allow the impulse traversing the accessory pathway to activate all or most of both ventricles. ${ }^{14} 15$

\section{Discussion}

\section{DIFFICULTIES IN DETERMINING LOCATION OF ACCESSORY PATHWAY}

The major problem in diagnosing the location of the accessory pathway in this case was related to the occurrence of pre-excitation only at very long cycle lengths (Fig. 2 and 3). Nevertheless, analysis of the surface electrocardiographic and intracardiac electrophysiological events suggested that the accessory pathway was right sided. Vectorial analysis of standard and chest leads showed that the abnormal ventricular depolarisation occurred in a superior, leftward, and posterior direction (Fig. 1 to 3 ). Moreover, during maximal pre-excitation the initial slurring was located partly in the left anterior quadrant and partly in the left posterior quadrant. Even in the absence of spatial vectorcardiograms these findings can be construed to indicate that the

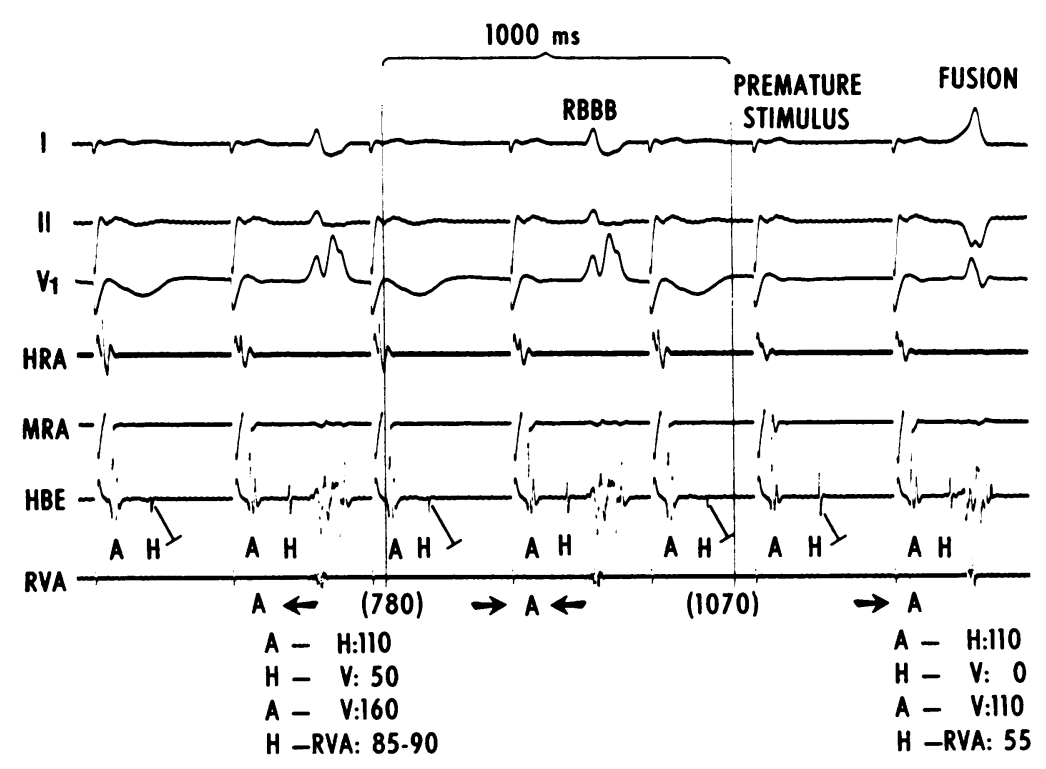

Fig. 2 Intracardiac recordings (obtained during atrial pacing) showing : (a) pure right bundlebranch block (RBBB) in conducted impulses (first two QRS complexes); (b) $2: 1$ (infraHisian) $A V$ block resulting from the association of persistent $R B B B$ with tacycardia-dependent

(phase 3) left bundle-branch block (LBBB); (c) tachycardiadependent (phase 3) block in the accessory pathway; and (d) fusion resulting from the coexistence of right bundle-branch block with WPW type $B$ (last QRS complex). Numbers between arrows refer to the interval between two consecutively conducted atrial ( $A$ ) impulses. All values are expressed in ms. $H R A$ : high right atrium; $M R A$ : mid-right atrium; $R V A$ : right ventricular apex; $A$ : atrial electrogram recorded in the $H$ is bundle electrogram (HBE) lead;

$V$ : onset of depolarisation, regardless of the pathway responsible for initial ventricular activation. 
accessory pathway ended in a right-inferior, probably mid-septal, site. ${ }^{16}$

On the other hand, the intracardiac studies showed that the estimated conduction time between the pre-excited site and the right ventricular apex in beats with delta waves ( $35 \mathrm{~ms}$ ) was similar to that previously reported in patients with WPW type B $(40$ to $50 \mathrm{~ms}){ }^{15}$ These values were significantly shorter than those reported in patients with WPW type A (120 to $160 \mathrm{~ms}) .^{14}$

Theoretically, the distance between the ventricular end of the accessory pathway and the recording electrodes can be determined if the conduction time, conduction velocity, and location of conduction pathways are known. Unfortunately, these indices have not been adequately defined for the human ventricles: the reported conduction times have ranged widely between $440 \mathrm{~mm} / \mathrm{s}$ (in revived hearts) to $1200 \mathrm{~mm} / \mathrm{s}$ (in patients with implanted left ventricular pacemakers). ${ }^{17} 18$ In canine hearts Lewis found that the conduction velocity through the ordinary muscle of the free right ventricular wall was approximately 400 $\mathrm{mm} / \mathrm{s}^{19}$

Calculations based on these values suggest that the distance between the site of emergence from the accessory pathway and the right ventricular apex in our two cases could have ranged between $15 \cdot 4$ and $42 \mathrm{~mm}$.

\section{TACHYCARDIA-DEPENDENT (PHASE 3)}

\section{BLOCK IN ACCESSORY PATHWAY}

The absence of pre-excitation (before the development of 2:1 AV block) in all tracings showing sinus tachycardia (Fig. 1A) could have been the result of tachycardia-dependent (phase 3) block in the accessory pathway. ${ }^{20}$ However, this assumption was not proved as electrophysiological studies were not performed.

In our opinion the diagnosis of the conduction disturbance under consideration cannot always be made exclusively from the surface electrocardiogram since multiple factors can produce false patterns of tachycardia-dependent (phase 3) block in the accessory pathway. ${ }^{21}$ Foremost among these are the differences in conduction time through normal pathway and anomalous pathway.

Disappearance of pre-excitation at relatively high rates may simply be an expression of a sympathetic enhancement of AV nodal conduction without any change in the physiological properties of the accessory pathway. In addition, this phenomenon has also been ascribed to a shift in the site of impulse initiation, to differential intra-atrial delays, and to changes in the site and mode of entry into the AV node and accessory pathways. ${ }^{21}{ }^{22}$ Similarly, the exposure of pre-excitation during sinuatrial slowing produced by carotid sinus massage ${ }^{20}$ may be explained entirely by vagal-induced AV nodal block of high degree.

The method used to unmask the pre-excitation in Fig. 2 and 3 was different from that used by Przybylski et al. ${ }^{20}$ Fig. 2 and 3 also show that the occurrence of pre-excitation at long cycle lengths was related to: (a) the duration of the phase 3 block in the accessory pathway; and (b) differences in conduction time through the latter and through the normal pathway.

RIGHT BUNDLE-BRANCH BLOCK IN PATIENTS WITH WOLFF-PARKINSON-WHITE SYNDROME The association of right bundle-branch block with WPW type A, or type $B$, has been well recognised and thoroughly discussed. ${ }^{1-7}$
Fig. 3 Atrial pacing with: (a) pure right bundle-branch block in conducted impulses (first QRS complex in the left, and in the right panel); (b) $2: 1$ $A V$ block resulting from the association of persistent right bundle-branch block and tachycardia-dependent (phase 3) block in the accessory pathway; (d) fusion resulting from the coexistence of right bundle-branch block with WPW type B (second $Q R S$ complex in the left panel); and $(e)$ ventricular complex (last in the right panel) with a pure, or almost pure, WPW type $B$ morphology.
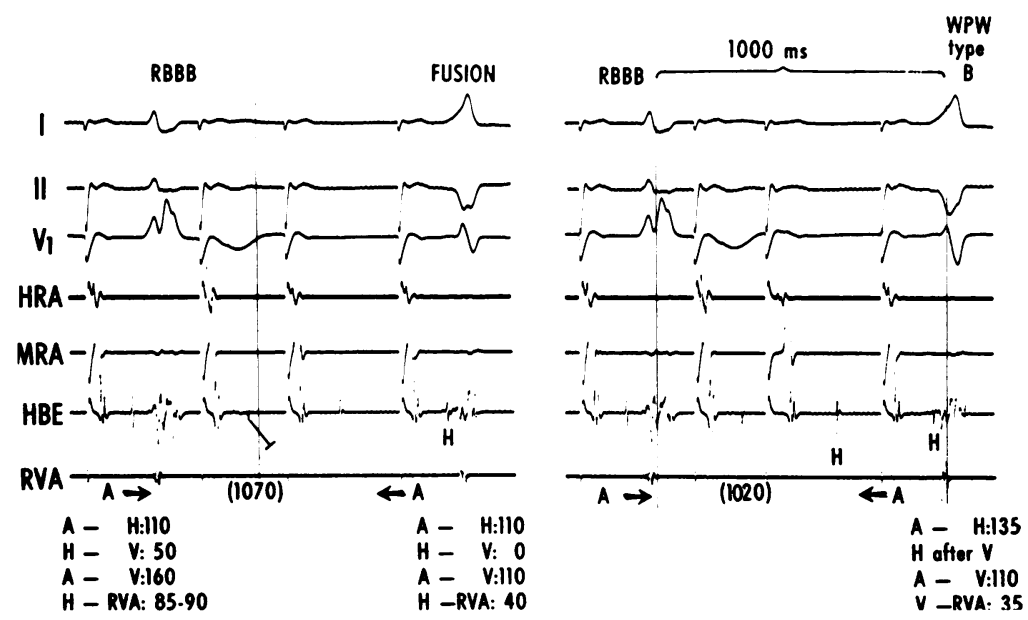
LEFT BUNDLE-BRANCH BLOCK IN PATIENTS WITH WOLFF-PARKINSON-WHITE

SYNDROME TYPE A

In contrast, as recently emphasised by Krikler et $a .^{13}$ fewer reports have dealt with left bundlebranch block coexisting with WPW type A. ${ }^{10-12}$ Moreover, Krikler et al. ${ }^{13}$ also reviewed the published reports and presented information from two personal cases in which electrophysiological studies were performed.

\section{RATE-UNRELATED LEFT BUNDLE-BRANCH BLOCK IN PATIENTS WITH \\ WOLFF-PARKINSON-WHITE SYNDROME TYPE B}

In the very few reports dealing with this combination, the diagnosis was made by electrocardiographic and (or) vectorcardiographic analysis. However, as stated by Krikler et al. ${ }^{13}$ 'final proof requires electrophysiological techniques'. Therefore, it is possible to question some tracings (showing short PR intervals and very wide $Q R S$ complexes) which were attributed to WPW type B coexisting with left bundle-branch block either because 'after the endpoint of pre-excitation there was further prolongation of the QRS', ${ }^{23}$ or because 'horizontal QRS loops with leftward and posteriorly oriented delta and maximal vectors were followed by additional mid-delays and slurrings'.

In the light of recently acquired information they can be explained by assuming exclusive AV conduction through a right-sided accessory pathway, without necessarily postulating the concomitant existence of left bundle-branch block. ${ }^{16}$ This accessory pathway could be atrioventricular ('Kent') as well as fasciculoventricular ('Mahaim'). Electrophysiological verification is essential, because similar patterns can occur when the ventricles are activated almost simultaneously by impulses emerging from a right anterior (parietal or septal) accessory pathway and from the right bundle-branch (in cases where the left bundle-branch is completely blocked). This was shown in the studies of Latour and Puech ${ }^{24}$ and Mendoza et $a .^{25}$ where simulated (catheterinduced) right septal pre-excitation was produced in patients with left bundle-branch block. The ventricular complexes resulting from iatrogenic right ventricular pre-excitation were as wide as (but of different morphology from) those occurring when sinus rhythm (with left-bundle-branch block) was present.

TACHYCARDIA-DEPENDENT (PHASE 3)

LEFT BUNDLE-BRANCH BLOCK IN PATIENTS WITH WOLFF-PARKINSON-WHITE SYNDROME As far as we know there is only one reported case where the authors postulated that this conduction disturbance might have been present in a patient with WPW syndrome. According to Krikler et al. ${ }^{13}$ the left bundle-branch block occurring in one of the cases (with WPW type A) reported by Pick and Fisch $^{1}$ was probably tachycardia-dependent. In our patient this diagnosis was possible because, regardless of the underlying electrophysiological mechanism, pre-excitation did not occur during sinus tachycardia (Fig. 1A). Furthermore, left bundle-branch block was not seen when preexcitation was abolished with intravenous procainamide while the rate was slower (Fig. 1D). After development of persistent right bundlebranch block, the tachycardia-dependent (phase 3) left bundle-branch block naturally coexisted with the former, thus being manifested as infra-Hisian (bilateral bundle-branch) block in alternate beats (Fig. 2 and 3).

\section{VARYING QRS MORPHOLOGIES}

The patient discussed in this communication is unique, in that she had, at one time or another, ventricular complexes representing: (a) exclusive normal (AV node-His Purkinje) pathway conduction without bundle-branch block (Fig. 1D); (b) predomonant or exclusive AV conduction through a right-sided accessory pathway (Fig. 3, right panel); (c) pure right bundle-branch block (Fig. 2 and 3); (d) pure left bundle-branch block (Fig. 1A); (e) fusion complexes resulting from the coexistence of (a) and (b) (Fig. 1B and C); and (f) fusion complexes resulting from the coexistence of (b) and (c) (Fig. 2 and 3). However, fusion caused by simultaneously occurring WPW type $B$ and left bundle-branch block could not be identified, and this association still requires further electrophysiological evaluation.

\section{References}

${ }^{1}$ Pick A, Fisch C. Ventricular pre-excitation (WPW) in the presence of bundle branch block. Am Heart $\mathcal{F}$ 1958; 55: 504-12.

${ }^{2}$ Castellanos A Jr, Mayer JW, Lemberg L. The electrocardiogram and vectorcardiogrrm in WolffParkinson-White syndrome associated with bundle branch block. Am $¥$ Cardiol 1962; 10: 657-66.

${ }^{3}$ Robertson PGC, Emslie-Smith D, Lowe KG, Watson $H$. The association to type $B$ ventricular preexcitation and right bundle branch block. Br Heart $\mathcal{f}$ 1963; 25: 755-62.

${ }^{4}$ Schamroth L, Krikler DM. Location of the preexcitation areas in the Wolff-Parkinson-White syndrome. Am f Cardiol 1967; 19: 889-91.

${ }^{5}$ Durrer D, Schuilenburg RM, Wellens HJJ. Preexcitation revisited. Am $\mathcal{F}$ Cardiol 1970; 25: 690-7. 
${ }^{6}$ Castellanos A Jr, Castillo CA. His bundle recordings in right bundle branch block coexisting with iatrogenic right ventricular pre-excitation. Br Heart $\mathcal{F}$ 1972; 34: 153-9.

${ }^{7}$ Coumel Ph, Attuel P. Reciprocating tachycardia in overt and latent pre-excitation. Influence of functional bundle branch block on the rate of the tachycardia. Eur f Cardiol 1974; 1: 423-36.

${ }^{8}$ Lombardi M, Masini G. La pre-eccitazione ventricolare: contributo clinico-sperimentale. Milan: Ricordati, 1966: 83.

${ }^{8}$ Scherf D, Bornemann C. Two cases of pre-excitation syndrome. F Electrocardiol 1969; 2: 177-84.

${ }^{10}$ Denes $\mathrm{P}$, Goldfinger $\mathrm{P}$, Rosen KM. Left bundle branch block and intermittent type A pre-excitation. Chest 1975; 68: 356-8.

${ }^{11}$ Touboul P, Huerta F, Arnaud P, Porte J, Delahaye JP. Etude électrophysiologique de deux cas de préexcitation ventriculaire compatibles avec la présence de fibres de Mahaim. Arch Mal Coeur 1975; 68: 84151.

${ }^{12}$ Baudouy M, Molina B, Varenne A, Guiran JB. Syndrome de Wolff-Parkinson-White du type 'A' associé à un bloc de la branche gauche. Étude electrocardiographique, vectorcardiographique et électrophysiologique endocavitaire. Arch Mal Coeur 1976; 69: 523-32.

${ }^{13}$ Krikler D, Coumel Ph, Curry P, Oakley C. WolffParkinson-White syndrome type A obscured by left bundle branch block. Eur $\mathcal{C}$ Cardiol 1977; 5: 49-62.

${ }^{14}$ Castillo CA, Castellanos A Jr, Befeler B, Myerburg RJ, Agha AS, Vagueiro MC. Arrival of excitation at right ventricular apical endocardium in Wolff-ParkinsonWhite syndrome type $A$, with and without right bundlebranch block. Br Heart f 1973; 35: 594-600.

${ }^{15}$ Befeler B, Castellanos A Jr, Castillo CA, Agha AS, Vagueiro MC, Myerburg RJ. Arrival of excitation at the right ventricular apical endocardium in WolffParkinson-White syndrome type B. Circulation 1973; 48: $655-60$.

${ }^{16}$ Castellanos A Jr, Agha AS, Portillo B, Myerburg RJ. Usefulness of vectorcardiography combined with His bundle recordings and cardiac pacing in evaluation of the pre-excitation (Wolff-Parkinson-White) syndrome. Am 7 Cardiol 1972; 30: 623-8.

${ }^{17}$ Durrer D, van Dam RTh, Freud GE, Janse MJ, Meijler FL, Arzbaecher RC. Total excitation of the isolated human heart. Circulation 1970; 41: 899-912. ${ }^{18}$ Linenthal AJ, Zoll PM. Ventricular fusion beats during electric stimulation in man. Application to conduction velocity and anomalous A-V excitation. Circulation 1965; 31: 651-60.

${ }^{19} \mathrm{Lewis}$ T. The mechanisms and graphic registration of the heart beats. London: Shaw \& Sons, 1925: 93, 94. ${ }^{20}$ Przybylski J, Chiale PA, Quinteiro RA, Elizari MV, Rosenbaum MB. The occurrence of phase-4 block in the anomalous bundle of patients with WolffParkinson-White syndrome. Eur f Cardiol 1975; 3: 267-80.

${ }^{21}$ Castellanos A, Aranda JM, Gutierrez R, Befeler B. Effects of pacing site on QRS morphology in WolffParkinson-White syndrome. With special reference to 'pseudo-tachycardia-dependent block in accessory pathway' and 'atrial gap'. Br Heart f 1976; 38: 363-8. ${ }^{22}$ Garcia OL, Castellanos A, Sung RJ, Gelband H. Exposure of concealed right bundle branch block in Wolff-Parkinson-White syndrome type $B$ by pacing from the vicinity of the A-V node. Am Heart $f$ 1978; 96: $662-8$.

${ }^{23}$ Follath F, Hallidie-Smith KA. Unusual electrocardiographic changes in Ebstein's anomaly. Br Heart $\mathrm{f}$ 1972; 34: 513-9.

${ }^{24}$ Latour H, Puech P. Electrocardiographic endocavitaire. Paris: Masson et Cie, 1957; 123, 282.

${ }^{25}$ Mendoza IJ, Sung RJ, Mallon SM, Castellanos A, Myerburg RJ. Multiple intracardiac recordings in evaluation of patterns occurring during attempted His bundle pacing in man. Am $\mathcal{F}$ Cardiol 1978; 41 : 1068-74.

Requests for reprints to Dr Agustin Castellanos, Division of Cardiology (D-39), University of Miami School of Medicine, PO Box 016960, Miami, Florida 33101, USA. 